Remoção do Corante Textil Violeta Cristal Utilizando Argila Maranhese de Montes Altos Como Adsorvente

\author{
Guida, I. I. S.; Falcão, S. S.* \\ Rev. Virtual Quim., 2018, 10 (4), 1087-1099. Data de publicação na Web: 31 de agosto de 2018 \\ http://rvq.sbq.org.br
}

\title{
Removal of Crystal Violet Textile Using Clay Maranhese of High Mounts as Adsorvent
}

\begin{abstract}
The pollution of water resources has generated great concern for society. One of the main responsible is the textile sector. Among the most promising alternatives for treatment of textile effluents is the adsorption. Thus, this study aims to evaluate the adsorption potential of the crystal violet dye by the Montes Altos clay. The solid was collected in the municipality of Montes Altos-MA and activated with $\mathrm{HCl}$; characterized by infrared spectroscopy, X-ray diffraction and $\mathrm{pHpzc}$. The influence of $\mathrm{pH}$ on crystal violet dye adsorption was determined by batch. Two models were tested: pseudo-first order and pseudosecond order to describe the behavior of the adsorption kinetics of the crystal violet dye by the Montes Altos clay. By characterization the main vibrational stretches and the phases of the clays were confirmed. The adsorbed amount was higher at $\mathrm{pH}$ above pHpcz (2.8). showing that the material is suitable for removal of cationic dye. It was possible to calculate the parameters that govern the kinetic models, where $(\mathrm{k})$ is the mass transfer constant for the models presented and (Qe) is the maximum theoretical adsorption capacity at equilibrium. Finally, the equilibrium time for the adsorption of the crystal violet dye (VC) solution was 60 ( $\mathrm{min})$.
\end{abstract}

Keywords: Clay; Adsorption; Dyes.

\section{Resumo}

A poluição dos recursos hídricos vem gerando grande preocupação à sociedade. Um dos principais responsáveis é o setor têxtil. Entre as alternativas mais promissoras de tratamento dos efluentes têxteis está a adsorção. Assim, este estudo tem como objetivo avaliar o potencial de adsorção do corante violeta cristal pela argila de Montes Altos. O sólido foi coletado no município de Montes Altos-MA e ativado com $\mathrm{HCl}$; caracterizado por espectroscopia de infravermelho, difração de raios X e pHpzc. A influência do pH na adsorção da solução do corante violeta cristal VC foi determinado em batelada. Foram testados dois modelos: pseudo-primeira ordem e pseudo-segunda ordem para descrever o comportamento da cinética de adsorção do corante violeta cristal pela argila de Montes Altos. Pelas caracterizações foram confirmados os principais estiramentos vibracionais e as fases das argilas. A quantidade adsorvida foi maior em pH acima do pHpcz (2,8). mostrando que o material é adequado para a remoção de corante catiônico. Foi possível calcular os parâmetros que regem os modelos cinéticos, onde o ( $\mathrm{k}$ ) é a constante de transferência de massa para os modelos apresentados e o (qe) é a capacidade máxima de adsorção teórica no equilíbrio. Por fim, o tempo de equilíbrio para a adsorção da solução do corante violeta cristal foi de 60 (min).

Palavras-chave: Argila; Adsorção; Corante.

\footnotetext{
* Universidade Federal do Maranhão, Departamento de Química, Campus do Bacanga, CEP 65080-420, São Luís-MA, Brasil.

Mitaloiury15@gmail.com DOI: $10.21577 / 1984-6835.20180076$
} 


\section{Remoção do Corante Textil Violeta Cristal Utilizando Argila Maranhese de Montes Altos Como Adsorvente \\ Italo lury de Souza Guida, * Suringo Sousa Falcão}

Universidade Federal do Maranhão, Departamento de Química, Campus do Bacanga, CEP 65080-420, São Luís-MA, Brasil.

*italoiury15@gmail.com

Recebido em 18 de maio de 2018. Aceito para publicação em 17 de agosto de 2018

\section{Introdução}

\section{Parte Experimental}
2.1. Materiais e Reagentes
2.2. Preparo do Adsorvente
2.3. Caracterização do Adsorvente
2.4. Influencia do pH e Cinética de Adsorção

\section{Resultados e Discussão}

3.1. Espectroscopia de Infravermelho e Difração de Raios X para a Argila in Natura e Ativada

3.2. Determinação do Ponto Zero de Carga do Adsorvente

3.3. Efeito do $\mathrm{pH}$

3.4. Cinética de Adsorção e Modelagem Matemática

\section{Conclusão}

\section{Introdução}

A poluição ambiental tem se mostrado como um sério problema enfrentado pela sociedade trazendo consigo altos riscos à saúde humana, prejudicando principalmente a fauna e a flora. Entre vários problemas que o homem causa a natureza, a contaminação de efluentes a partir do descarte de águas residuais de processos industriais é de grande preocupação para a análise dos impactos ambientais causados pela mão humana a natureza. ${ }^{1,2}$ Entre as indústrias que mais despejam esses efluentes, a alimentícia e a têxtil são as que mais causam impactos ambientais através de água contaminada principalmente de corantes como a anilina utilizada para confeite de bolos. ${ }^{3,4}$ Contudo, a indústria têxtil utiliza corantes para a confecção de tecidos que em sua composição apresentam metais pesados como mercúrio, cromo entre outros que são altamente prejudiciais a vida. ${ }^{5}$

Esses metais presentes nos corantes podem sofrer lixiviação contaminando não somente rios e lagos, mas uma das principais fontes de água potável no nosso país, os 
lençóis freáticos. ${ }^{6}$ Nesse contexto em que o homem vem causando a natureza, e com intuito de prevenir a contaminação desses reservatórios de água, a adsorção é uma técnica eficiente, promissora e economicamente viável. O Violeta Cristal é também conhecido como Violeta básico 3, é amplamente usado como corante roxo para têxteis tais como algodão e seda, e em tintas de impressão. ${ }^{7,8}$ Existem vários processos de purificação dessas águas no qual podemos citar a extração por solventes, troca iônica, entre outros, porém, muitos desses métodos são de um custo elevado além de alguns gerarem resíduos, o que é outro problema ambiental. No entanto, a adsorção desses corantes utilizando as argilas é extremamente eficaz e de baixo custo, pois elas podem ser encontradas por toda parte e são fácilmente extraídas do ambiente apesar de também gerarem resíduos. Contudo, as argilas podem sofrer o processo de dessorção para serem reutilizadas e tornar o processo de adsorção viável economicamente.

A adsorção é um fenômeno fisico-químico que consiste na agregação de determinadas espécies, (adsorvato) na superfície de um material (adsorvente). ${ }^{9,10}$ Há grandes vantagens desse processo quando comparado a outros. Esse método permite que o adsorvente possa ser regenerado a partir do processo de desorção, para posteriormente ser reutilizado. ${ }^{11}$ Isto equivale a uma vantagem deste método em relação a outros meios, que geralmente ocasionam formação de produtos tóxicos. ${ }^{12} \mathrm{Um}$ material bastante utilizado é o carvão ativado, que oferece alta eficiência devido as características de sua estrutura atômica oferecendo alta área de superfície e natureza química. ${ }^{1}$ No entanto, seu uso tem algumas desvantagens, como baixa seletividade e eficiência para certos corantes dispersos ${ }^{13}$ bem como as perdas durante o processo de recuperação. ${ }^{14}$

As argilas são poderosos adsorventes, pois em sua superficie ha uma grande concentração de cargas, o que favorece a adsorção, além de serem encontradas em todos os lugares do planeta ${ }^{15}$ porém, dependendo da classe de argila utilizada, é necessário um tratamento químico para melhor a utilização de sua capacidade de adsorção já que na natureza as argilas encontram-se misturadas a outros compostos como a areia, o que não favorece a adsorção.

Esse estudo busca então caracterizar o adsorvente e avaliar a capacidade de adsorção da argila maranhense de Montes Altos na remoção do corante violeta cristal e avaliar o melhor modelo que descreve a cinética de adsorção assim como os parâmetros das equações dos modelos a partir da modelagem matemática, para consolidar um meio de tratamento eficaz de fonte renovável e barata aos efluentes despejados na natureza.

\section{Parte Experimental}

\subsection{Materiais e Reagentes}

A argila foi coletada no munícipio maranhense de Montes Altos (latitude $05^{\circ} 48^{\prime} 26^{\prime \prime}$ e longitude $47^{\circ} 10^{\prime} 08^{\prime \prime}$ ). Todos os reagentes utilizados foram de grau analítico. $O$ corante textil violeta cristal foi produzido por DyStar. O corante possuia uma pureza de 99 $\%$. A Figura 1 apresenta a estrutura química do corante. 


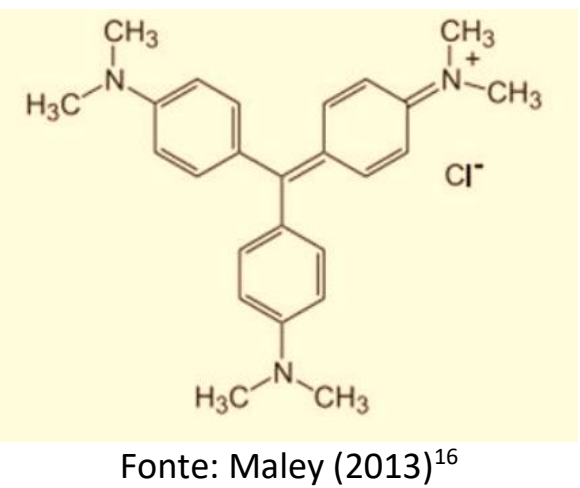

Figura 1. Estrutura química do corante violeta cristal

\subsection{Preparo do adsorvente}

A argila passou por um processo manual de limpeza, posteriormente, foi lavada com água destilada e seca a $110^{\circ} \mathrm{C}$ por $24 \mathrm{~h}$. Em seguida, foi triturada e peneirada para a faixa granulométrica de 25 a $75 \mu \mathrm{m}$. Depois, a argila foi ativada com $\mathrm{HCl} 3,0 \mathrm{~mol} \mathrm{~L}^{-1}$. A ativação química foi realizada colocando-se $100 \mathrm{~g}$ da argila com $1000 \mathrm{~mL}$ de solução de ácido sob refluxo durante $2 \mathrm{~h}$ a $90^{\circ} \mathrm{C}$ e agitação constante. Após o tratamento, a suspensão foi filtrada e o precipitado foi lavado com água destilada até a condutividade constante. Secou-se a argila ativada em estufa a $105^{\circ} \mathrm{C}$ por $48 \mathrm{~h}$. Em seguida, a argila foi triturada e peneirada para a faixa granulométrica de 25 a $75 \mu \mathrm{m}$.

\subsection{Caracterização do adsorvente}

As argilas in natura e ativada foram caracterizadas por espectroscopia na região do infravermelho, difração de raios $\mathrm{X}$ e pHpcz. ${ }^{11}$ Os espectros de infravermelho foram obtidos utilizando um espectrômetro Shimadzu, modelo IRPrestige-21, na faixa de 4000 a $400 \mathrm{~cm}^{-1}$. Utilizou-se a técnica da pastilha (disco prensado), que usa brometo de potássio seco e pulverizado. Misturou-se uma quantidade $(0,5$ a $1,0 \mathrm{mg})$ do adsorvente com cerca de $100 \mathrm{mg}$ de brometo de potássio seco e pulverizado. A mistura foi prensada em moldes específicos, sob pressão de 10 a 15 Kpsi até formar um disco transparente. $\mathrm{O} \mathrm{pH}$ no ponto de carga zero ( $\mathrm{pHpcz}$ ) foi obtido colocando-se $100 \mathrm{mg}$ da argila ativada em contato com $25 \mathrm{~mL}$ de solução $0,1 \mathrm{~mol} \mathrm{~L}^{-1}$ de $\mathrm{KCl}$ em diferentes $\mathrm{pH}$ 's, variando-se de 1 a 12 (ajustados com $\mathrm{HCl} / \mathrm{NaOH}$ ). A mistura permaneceu sob agitação constante por $24 \mathrm{~h}$ a $25^{\circ} \mathrm{C}$, após o tempo, separou-se a argila por centrifugação e determinou-se $\mathrm{o} p \mathrm{pH}$ do sobrenadante. Então, o valor do $\mathrm{pHpcz}$, no qual a variação entre o pHinicial e pHfinal é nula, foi determinado graficamente.

\subsection{Influencia do pH e cinética de adsorção}

A influência do $\mathrm{pH}$ no processo de adsorção do corante foi determinada colocando-se $100 \mathrm{mg}$ da argila ativada em contato com $25 \mathrm{~mL}$ da solução do corante violeta cristal $\left(100 \mathrm{mg} \mathrm{L}^{-1}\right)$ em $\mathrm{pH}^{\prime} \mathrm{s}$ variando de 2 a 11 ajustados com $\mathrm{HCl}$ ou $\mathrm{NaOH}$, sob agitação constante por $24 \mathrm{~h}$ a $25^{\circ} \mathrm{C}$. Após esse tempo, o adsorvente foi separado por centrifugação e a concentração do corante foi determinada por espectrofotometria na região do UVvisível em $590 \mathrm{~nm}$.

Nos estudos cinéticos, $0,100 \mathrm{~g}$ do adsorvente foi colocado em contato com 25,0 $\mathrm{mL}$ da solução do corante com concentração de $100,0 \mathrm{mg} \mathrm{L}^{-1}$ e pH ideal nos tempos de 0 a $360,0 \mathrm{~min}$, sob agitação de $150 \mathrm{rpm}$ a 25 ․C. As cinéticas foram adequadas aos modelos de pseudo-primeira ordem e pseudo-segunda ordem conforme as Equações 1 e 2 já linearizadas. ${ }^{17,18}$ 
Guida, I. I. S.; Falcão, S. S.

$$
\log \left(q_{e}-q_{t}\right)=\log \left(q_{e}\right)-\frac{k}{2,303} t
$$

Onde, $k$ é a constante de taxa de adsorção de pseudo-primeira ordem $\left(\mathrm{min}^{-1}\right), t$ é o tempo de reação ( $\min ), q_{e}$ é a capacidade de

$$
\frac{t}{q_{t}}=\frac{1}{k q_{e}^{2}}+\frac{1}{q_{e}} t
$$

Onde, $k$ é a constante de velocidade de adsorção de pseudo-segunda ordem $\left(\mathrm{g}, \mathrm{mg}^{-1}\right.$ $\left.\min ^{-1}\right), q_{e}$ é a capacidade de adsorção no equilíbrio $\left(\mathrm{mg} \mathrm{g}^{-1}\right), q_{t}$ é a capacidade de adsorção em um tempo $\mathrm{t}\left(\mathrm{mg} \mathrm{g}^{-1}\right)$ e $t$ é o tempo de reação $(\mathrm{min})$. Os ensaios foram realizados

$$
q=\frac{\left(\mathrm{C}_{\mathrm{i}}-\mathrm{C}_{\mathrm{f}}\right) \times \mathrm{V}}{\mathrm{m}}
$$

Sendo $q$ a quantidade adsorvida $\left(\mathrm{mg} \mathrm{g}^{-1}\right) ; \mathrm{Ci}$ e Cf são, respectivamente, as concentrações inicial e final dos corantes ( $\left.\mathrm{mg} \mathrm{L}^{-1}\right) ; \mathrm{m}(\mathrm{g})$ é a massa do adsorvente e $V(L)$ é o volume de solução do corante utilizado.

\section{Resultados e Discussão}

3.1 Espectroscopia de infravermelho e difração de raios $X$ para a argila in natura $e$ ativada adsorção no equilíbrio $\left(\mathrm{mg} \mathrm{g}^{-1}\right)$ e $q_{\mathrm{t}}$ é a capacidade de adsorção em um tempo $\mathrm{t}(\mathrm{mg}$ $\left.\mathrm{g}^{-1}\right)$.

em batelada. A absorbância foi medida no comprimento de onda de $590 \mathrm{~nm}$ para o corante violeta cristal, por espectrofotometria UV-visível e a quantidade adsorvida foi dada pela Equação 3.

Os espectros de infravermelho e os difratogramas das argilas in natura e ativada são mostrados nas Figuras 2 e 3 . Nos espectros é possível identificar que os estiramentos por volta de 3414 e $1630 \mathrm{~cm}^{-1}$ se referem ao grupo $\mathrm{O}-\mathrm{H}$, correspondente ao alongamento das moléculas de água adsorvida nas superfícies das argilas in natura e ativada. $O$ estiramento vibracional em 3620 $\mathrm{cm}^{-1}$, atribuído ao $\mathrm{Al}-\mathrm{OH}$ foi encontrado nas argilas. A banda em 1000 a $1200 \mathrm{~cm}^{-1}$, presente em todos os espectros, é atribuída a ligação Si-O-Si. 


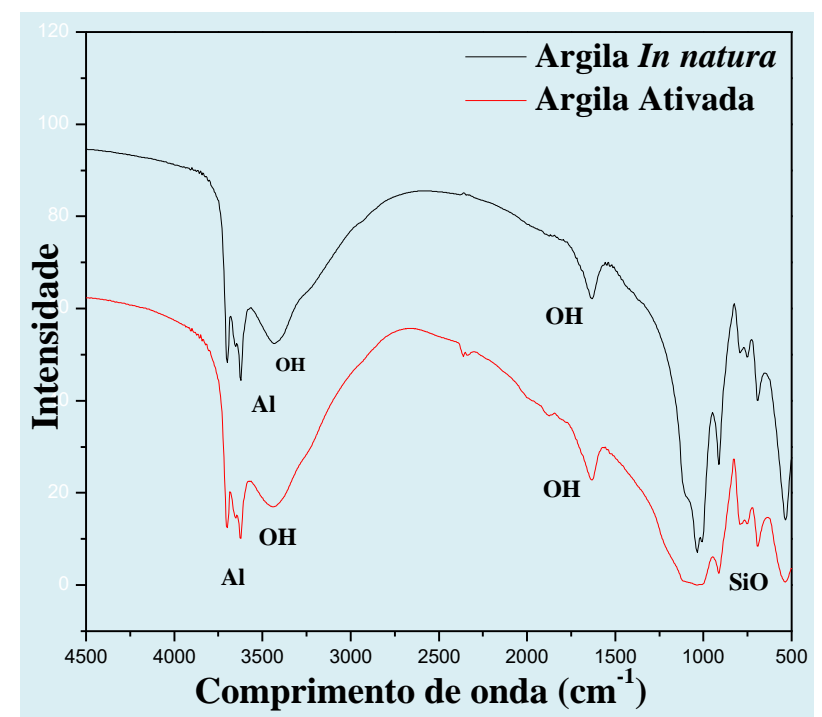

Figura 2. Espectros de infravermelho das argilas in natura e ativada

A vibração em $522 \mathrm{~cm}^{-1}$ é referente a interação Si-O-Al. Já a vibração em $470 \mathrm{~cm}^{-1}$ é atribuída a deformação do Si-O-Si. ${ }^{19-20,21}$ Observa-se que o tratamento ácido não provocou alterações significativas nos espectros de infravermelho da argila. Pelos difratogramas de raios $X$ observou-se grande quantidade de quartzo, o que nos confirrma o alto teor de areia. Ainda, é observada a presença de pequenos traços de caulinita.

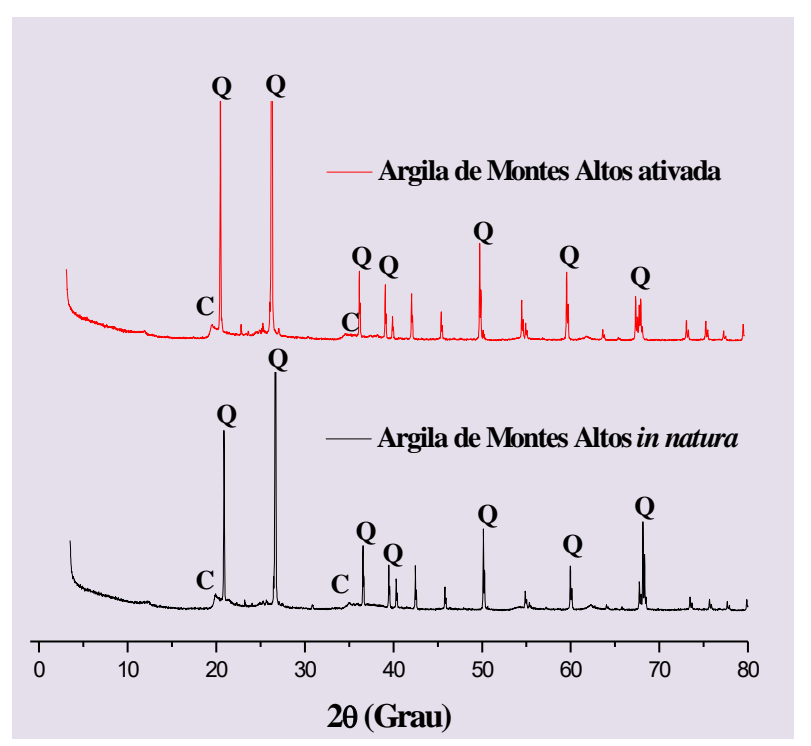

Figura 3. Difratogramas de raios $\mathrm{X}$ das argilas in natura e ativada $\mathrm{C}=$ caulinita, $\mathrm{Q}=$ quartzo

3.2 Determinação do ponto zero de carga do adsorvente
O ponto zero de carga é um parâmetro que indica o pH no qual um sólido particular não apresenta excesso de cargas líquidas em sua superfície. É importante conhecermos o 
pHpcz porque ele nos permite a previsão da carga superficial do adsorvente em função do $\mathrm{pH}$, onde em $\mathrm{pH}$ menor que o pHpcz a carga superficial do sólido é positiva, enquanto que para valores do $\mathrm{pH}$ superiores ao $\mathrm{pHpcz}$, a carga na superfície do adsorvente é negativa. A Figura 4 apresenta um um gráfico da variação de $\Delta \mathrm{pH}\left(\mathrm{pH}_{\text {inicial }}-\mathrm{pH}_{\text {final }}\right)$, em função do $\mathrm{pH}$ inicial $\left(\mathrm{pH}_{\text {inicial }}\right)$, para a argila de Montes Altos ativada.

O pHpcz foi estimado graficamente em 2.8. Valores similares para o pHpcz foram encontrados na literatura em determinação do ponto de carga zero em solos. ${ }^{22}$ Observa-se que abaixo de 2.8, a superfície do adsorvente está com excesso de cargas positivas, e acima desse valor a superfície está com excesso de cargas negativas, onde observa-se na Figura 4 que há maior concentração de cargas negativas que de cargas positivas.

Esse parâmetro nos diz então qual a natureza do corante que o adsorvente irá adsorver melhor. A argila de Montes Altos por apresentar superfície com maior concentração de cargas negativas adsorverá com maior eficiencia corantes catiônicos.

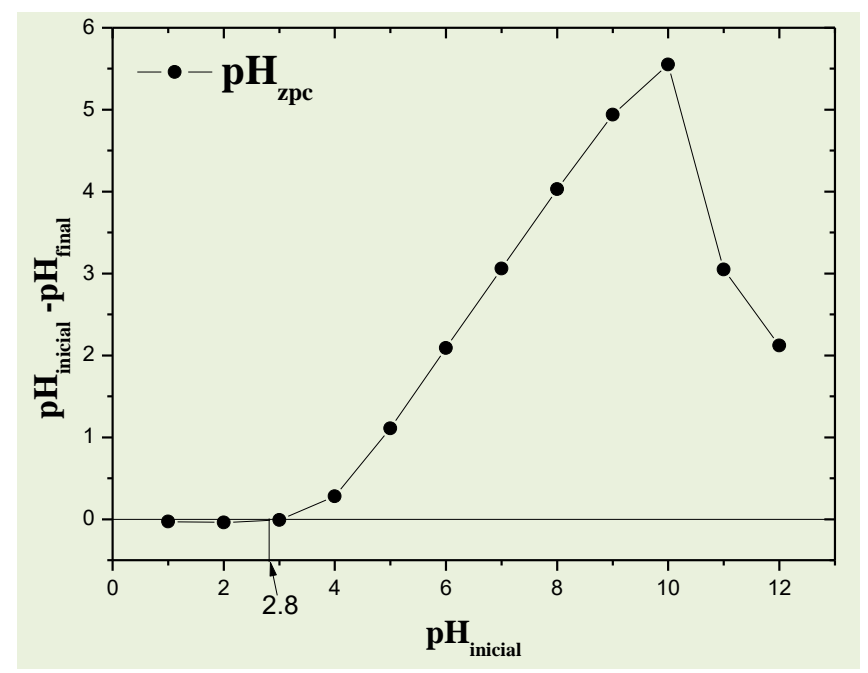

Figura 4. Ponto zero de carga para a argila de Montes Altos.

\subsection{Efeito do pH}

$\mathrm{O}$ efeito do $\mathrm{pH}$ no sistema é um elemento importante no processo de adsorção, pois a alteração do $\mathrm{pH}$ altera o equilíbrio dos grupos iônicos presentes no adsorvente e no corante influenciando a interação eletrostática. $\mathrm{Na}$ Figura 5 está representada a variação da quantidade adsorvida (Q) $\mathrm{mg} \mathrm{g}^{-1}$ de acordo com o pH. 


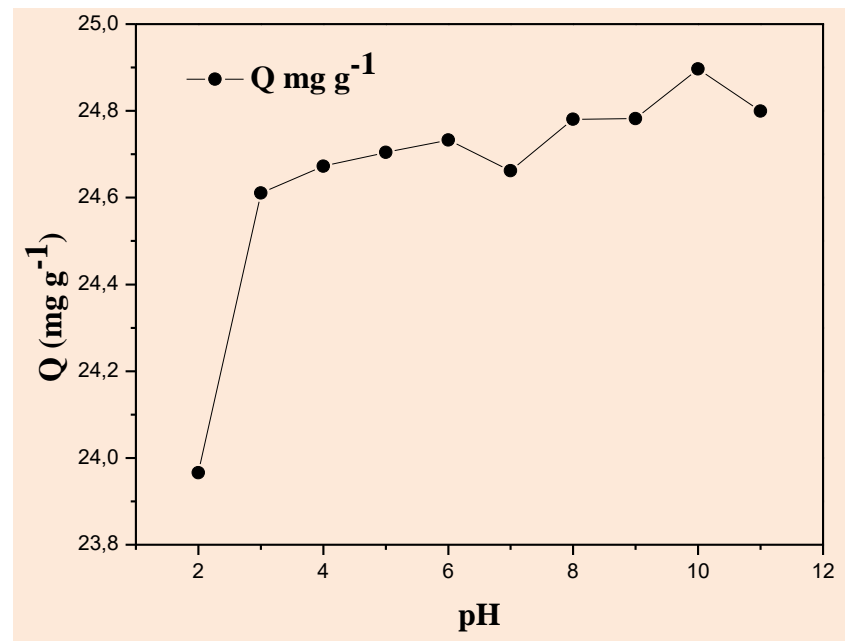

Figura 5. Quantidade adsorvida do corante em função do pH

Observa-se na Figura 5 que a quantidade adsorvida do corante é pouco dependente do $\mathrm{pH}$ para a argila de Montes Altos, pois a quantidade adsorvida permanece, aproximadamente, constante na faixa de $\mathrm{pH}$ de 3 a 11. Como esperado, a quantidade adsorvida aumentou com o aumento do $\mathrm{pH}$ devido as interações eletrostáticas da superfície do adsorvente com as cargas positivas do corante. $\mathrm{O}$ melhor $\mathrm{pH}$ de adsorção foi $\mathrm{pH}=10$ onde a quantidade adsorvida (Q) foi de $24,9 \mathrm{mg} \mathrm{g}^{-1}$.

Roulia e Vassiliadis ${ }^{23}$ analisaram a influência do $\mathrm{pH}$ na capacidade de adsorção da bentonita em adsorver corantes catiônicos e observaram que em meio ácido houve baixa adsorção, porém em meio básico ocorreu adsorção máxima do corante.

\subsection{Cinética de adsorção e modelagem matemática}

Com o intuito de conhecer algumas características sobre a cinética de adsorção do corante na argila, todos os dados experimentais obtidos no estudo cinético foram aplicados a dois modelos: pseudoprimeira ordem e pseudo-segunda ordem. Para a validação quantitativa, é necessário que os coeficientes de correlação sejam comparados. Pode-se verificar esse coeficiente a partir dos ajustes lineares de cada equação referente ao modelo cinético aplicado. 


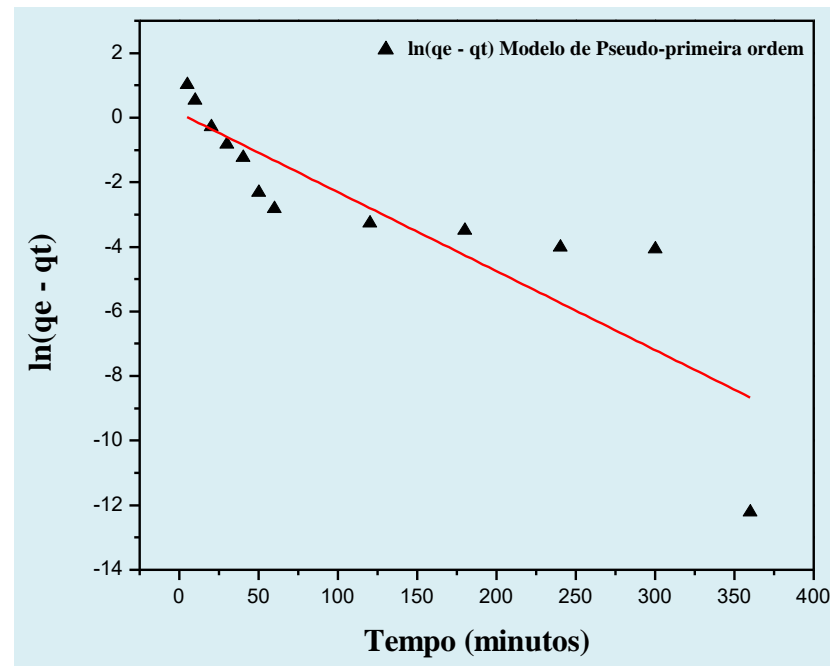

Figura 6. Modelo cinético de pseudo-primeira ordem , ajustado a cinética de adsorção do corante violeta cristal em argila de Montes Altos

Considerando o mecanismo de adsorção, os modelos cinéticos foram ajustados aos dados experimentais, para o sistema, solução do corante violeta cristal e argila de Montes altos através da linearização das equações diferenciais que regem os modelos de pseudoprimeira ordem e pseudo-segunda ordem obtendo-se as Equações 1 e 2.
Pode-se observar nas Figuras 6 e 7 que foram construídos os gráficos de $\log \left(q_{\max }-q_{t}\right)$ vs $t$ para o modelo de pseudo-primeira ordem e $t / q_{t}$ vs $t$ para o modelo de pseudo-segunda ordem respectivamente.

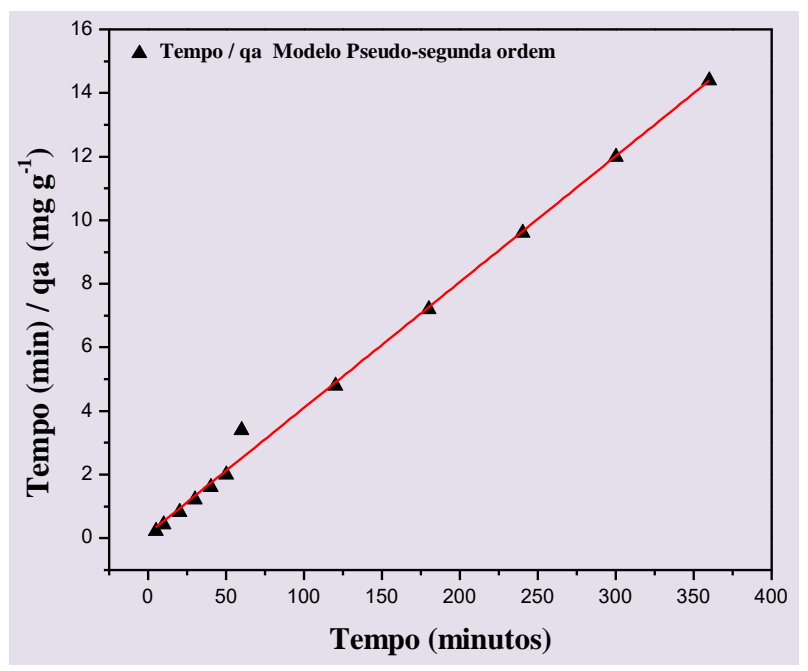

Figura 7. Modelo cinétido de pseudo-segunda ordem ajustado a cinética de adsorção do corante violeta cristal em argila de Montes Altos

Analisando a Figura 6, percebe-se que para o modelo de pseudo-primeira ordem, os dados cinéticos não se ajustaram bem. Já para a Figura 7 , o modelo cinético de pseudo- segunda ordem teve melhor ajuste. A Tabela 1 apresenta os dados obtidos a partir dos ajustes lineares para os modelos cinéticos apresentados. 
Tabela 1. Dados dos ajustes lineares a partir dos gráficos para os modelos cinéticos de pseudo-primeira ordem e pseudo-segunda ordem para o corante violeta cristal

\begin{tabular}{c|c|c|c|c}
\hline $\begin{array}{c}\mathbf{C} \\
\left(\mathrm{mg} \mathrm{g}^{-1}\right)\end{array}$ & Modelos cinéticos & $\begin{array}{c}\mathbf{q e} \\
\left(\mathrm{mg} \mathrm{g}^{-1}\right)\end{array}$ & $\mathbf{K}$ & $\mathbf{R}^{\mathbf{2}}$ \\
\hline \multirow{2}{*}{100} & P.primeira ordem & 0,97 & $\begin{array}{c}0,0560 \\
\left(\mathrm{~min}^{-1}\right)\end{array}$ & 0,73 \\
\cline { 2 - 5 } & P.segunda ordem & 25,31 & $\begin{array}{c}0,0015 \\
\left(\mathrm{~g} \mathrm{mg}^{-1} \mathrm{~min}^{-1}\right)\end{array}$ & 0,99 \\
\hline
\end{tabular}

A partir da análise dos dados na Tabela 1, percebe-se que o modelo de pseudo-segunda ordem se ajustou melhor aos dados, já que seu coeficiente de ajuste $\left(R^{2}\right)$ foi de 0,996 , diferente do modelo de pseudo-primeira ordem, onde $\circ\left(R^{2}\right)$ foi de 0,735 . Com os coeficientes angular e linear da reta obtida pelo modelo de pseudo-segunda ordem linearizado, foi possível calcular a capacidade de adsorção teórica $q_{e}$ que foi de 25,31 (mg g $\left.{ }^{1}\right)$. Comparando a capacidade de adsorção no equilíbrio teórica com a experimental que foi de aproximadamente $25,01\left(\mathrm{mg} \mathrm{g}^{-1}\right)$, percebese que o modelo descreve bem a cinética de adsorção do sistema solução do corante e argila de Montes Altos. Comparando ainda a quantidade adsorvida da argila de Montes Altos com adsorvontes padrão na literatura como o carvão ativado ${ }^{24}$ é possivel dizer que a argila de Montes Altos se mostrou um bom adsorvente.

A Figura 8 apresenta a cinética de adsorção do sistema VC e argila de montes altos. Observa-se que o tempo de equilíbrio nestas condições foi de aproximadamente $60 \mathrm{~min}$ para o VC. As quantidades adsorvidas aumentaram com o acréscimo do tempo de contato favorecendo a difusão do corante no meio até atingir o equilíbrio elevando a eficiência de adsorção das espécies em função da energia térmica do meio ${ }^{25}$.

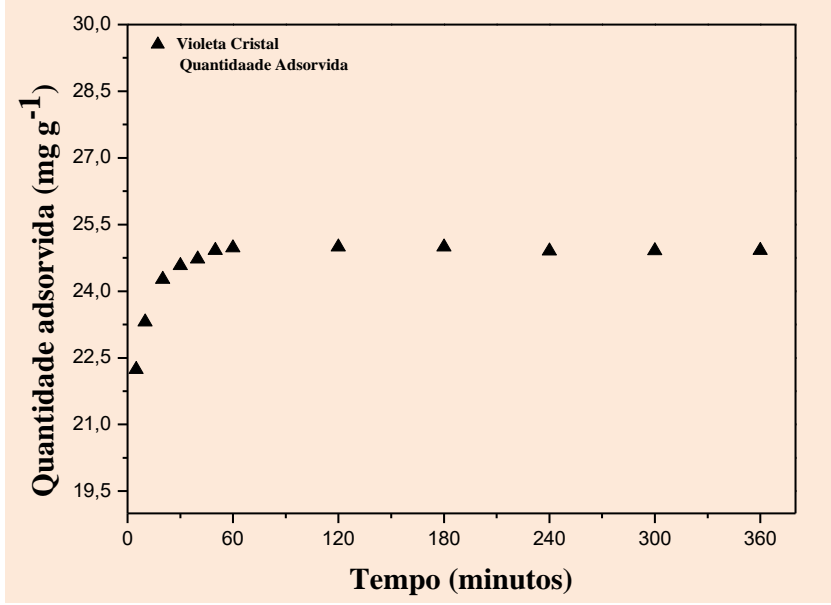

Figura 8. Cinética de adsorção do corante violeta cristal pela argila de Montes altos

Ainda com base na Figura 8, o tempo de equilíbrio foi estimado em 60 minutos. $O$ valor do tempo de equilíbrio para a argila de
Montes Altos foi semelhante ao encontrado na literatura para processo adsortivo de corantes por argilas esmectíticas. ${ }^{26,27}$ 
A capacidade de adsorção em porcentagem foi calculada a partir da concentração de equilíbrio experimental na cinética de adsorção que foi de aproximadamente $0,442 \mathrm{mg} \mathrm{L}^{-1}$ após 60 minutos. A partir desse valor e sabendo que a concentração inicial da solução do VC foi de $100 \mathrm{mg} \mathrm{L}^{-1}$, o percentual de remoção do VC em meio líquido pela argila de Montes Altos foi de $99,55 \%$. Mello et al (2013), ${ }^{28}$ estudou as propriedades de adsorção de uma argila esmectita na remoção de corantes têxteis e obteve um percentual de remoção de $97,87 \%$. Dominguini et al (2014) ${ }^{29}$ em um estudo sobre utilização de resíduos de materiais cerâmicos para adsorver o corante azul de metileno adquiriu um percentual de remoção de $76 \%$. Pode-se perceber com base na literatura que a argila de Montes Altos possui grande potencial para adsorção de corantes catiônicos como o VC.

Percebe-se ainda que a capacidade de adsorção foi diminuindo gradativamente até que depois de algum tempo o material já não adsorvia mais nada mesmo que o tempo passasse de $360 \mathrm{mim}$. Isso se deu devido à superfície do adsorvente está praticamente preenchida pelo corante e assim os sítios ativos do adsorvente já não interagiam mais com o corante.

\section{Conclusão}

A partir dos espectros de infravermelho e difratogramas de raios $X$ caracterizou-se as argilas in natura e ativada e observou que as estas são, majoritariamente, compostas por quartzo. Conclui-se, também, que o pH tem pouca influência na adsorção do corante têxtil violeta cristal. $\mathrm{O}$ pHpcz da argila ativada foi estimado em 2.8, mostrando que esse material é adequado para a remoção de corantes catiônicos. $\mathrm{O}$ estudo do $\mathrm{pH}$ mostrou que o melhor $\mathrm{pH}$ para a adsorção do corante violeta cristal foi $\mathrm{pH}=10$ onde a quantidade adsorvida foi de $24,9 \mathrm{mg} \mathrm{g}^{-1}$.

A partir do estudo cinético do corante violeta cristal utilizando a argila de Montes
Altos, podemos concluir que o modelo cinético de pseudo-segunda ordem se ajustou bem aos dados. A cinética de adsorção nos deu o tempo de equilíbrio do adsorvente, sendo que após esse tempo, (60 mim), o material não adsorve mais nada, sendo assim aproximado ao modelo cinético de pseudosegunda ordem.

Portanto, os objetivos desse estudo foram satisfeitos, já que as argilas são abundantes em todo o planeta terra, de baixo custo e se mostram como poderosos adsorventes no tratamento de efluentes provenientes da indústria têxtil e alimentícia

\section{Referências Bibliográficas}

${ }^{1}$ Ribeiro, G.; A.; C.; Silva, D.; S.; A.; Santos, C.; C.; Vieira, A.; P.; Bezerra, C.; W.; B.; B.; Tanaka, A.; A.; Santana, S.; A.; A. Removal of Remazol brilliant violet textile dye by adsorption using rice hulls. Polímeros, 2017 27, 16. [CrossRef]

2 Zeng, S.; Duan, S.; Tang, R.; Li, L.; Liu, C.; \& Sun, D. Magnetically separable Ni0.6Fe2.4O4 nanoparticles as an effective adsorbent for dye removal: Synthesis and study on the kinetic and thermodynamic behaviors for dye adsorption. Chemical Engineering Journal 2014, 258, 218. [CrossRef]

${ }^{3}$ Durán-Jiménez, G.; Hernández-Montoya, V.; Montes-Morán, M. A.; Bonilla-Petriciolet, A.; \& Rangel-Vázquez, N. A. Adsorption of dyes with different molecular properties on activated carbons prepared from lignocellulosic wastes by Taguchi method. Microporous and Mesoporous Materials 2014, 199, 99. [CrossRef]

${ }^{4}$ Guaratini, C. C. I.; Zanoni, M. V. B. Corantes Têxteis. Quimica Nova 2000, 23, 71. [CrossRef]

${ }^{5}$ Monash, P.; Pugazhenthi, G. Adsorption of crystal violet dye from aqueous solution using mesoporous materials synthesized at room temperature. Adsorption 2009, 15, 390. [CrossRef]

${ }^{6}$ Santos, S.; Maria Aparecida Pereira Pierangeli, M.; A.; P.; Ignácio, A.; R.; A.; Souza, C.; A. Teores de As, Cd e $\mathrm{Pb}$ em solos e 
sedimentos de áreas de garimpo de ouro nos municípios de Pontes e Lacerda e Nova Lacerda, Vale do Alto Guaporé, MT. Revista Brasileira de Geografia Física 2016, 9, 1805. [link]

${ }^{7}$ Conceição, A. C. L.; Diogo, H. P. Determinação de parâmetros cinéticos em fluxo com câmara de gradiente e deteç̧ão espectrofotométrica: aplicação à reação entre o violeta de cristal e o íon hidróxido. Quimica Nova 2013, 36, 905. [CrossRef]

${ }^{8}$ Mittal, A.; Mittal, J.; Malviya, A.; Kaur, D.; Gupta, V. K. Adsorption of hazardous dye crystal violet from wastewater by waste materials. Journal of Colloid and Interface Science 2010, 343, 463. [CrossRef]

${ }^{9}$ Adamson, A. W.; \& Gast, A. P. Physical chemistry of surfaces. New York: John Wiley \& Sons, 1997. [link]

${ }^{10}$ Yagub, M.; T.; Sen, T.; K.; Sharmeen Afroze, S.; Ang, H.; M. Advances in Colloid and Interface Science. Jornal homepage 2014, CIS01433. [CrossRef]

${ }^{11}$ Dallago, R.; M.; Smaniotto, A.; \& Oliveira, L. C. A. Resíduos sólidos de curtumes como adsorventes para a remoção de corantes em meio aquoso. Quimica Nova 2005, 28, 433. [CrossRef]

${ }^{12}$ Atadashi, I. M. Refining technologies for the purification of crude biodiesel. Applied Energy 2011, 88, 4239. [CrossRef]

${ }^{13}$ Babel, S.; Kurniawan, T. A. Low-cost adsorbents for heavy metals uptake from contaminated water: a review. Journal of Hazardous Materials 2003, 97, 219. [CrossRef] [PubMed]

${ }^{14}$ McKay, G. Colour removal by adsorption. American Dyestuff Reporter 1980, 69, 38. [link]

${ }^{15}$ Lopes, T. J. Adsorption of anthocyanins using clay-polyethylene nanocomposite particles. Applied Clay Science 2014, 87, 298. [CrossRef]

${ }^{16}$ Maley, A. M.; Arbiser, J. L. Gentian violet: a 19th century drug re-emerges in the 21st century. Experimental Dermatology, Copenhagen 2013, 22, 775. [CrossRef]

${ }^{17}$ Ho, Y. S.; Wase, D. A. J.; Forster, C. F. Kinetic studies of competitive heavy metal adsorption by sphagnum moss peat. Environmental Technology 1996, 17, 71. [CrossRef]

${ }^{18}$ Lagergren, S. On the theory of so-called adsorption dissolved substances. Handlingar Band 1898, 24, 1. [link]

${ }^{19}$ Ayari, F.; Srasra, M.; Trabelsi-Ayadi. Characterization of bentonitic clays and their use as adsorbent. Desalination 2005, 185, 391. [CrossRef]

${ }^{20}$ Kumar, P.; Raksh, V.; Jasra and Thirumaleshwara.; Bhat, S. G. Evolution of porosity and surface-acidity in montmorillonite clay on acid activation. Industrial \& Engineering Chemistry Research 1995, 34, 1440. [CrossRef]

${ }^{21}$ Vicente, M. A.; Suáres, M.; Lópes-Gonzáles, J. D.; Bañares-Muñoz, M. A. Characterization, surface area, and porosity analyses of the solids obtained by acid leaching of a saponite. Langmuir 1996, 12, 566. [CrossRef]

${ }^{22}$ Raij, B. V. Determinação do ponto de carga zero em solos. Bragantia 1973, 32, 337. [CrossRef]

${ }^{23}$ Roulia, M.; Vassiliadis, A.; A. Sorption characterization of a cationic dye retained by clays and perlite. Microporous and Mesoporous Materials 2008, 116, 732. [CrossRef]

${ }^{24}$ Araki, P. H. H. Trabalho de conclusão de curso, Universidade Tecnológica Federal do Paraná, 2013. [link]

${ }^{25}$ Souza, J. L; Dissertação de mestrado, Universidade Federal do Maranhão, 2009. [link]

${ }^{26}$ Duarte-Neto, J. F.; Menezes, R. R.; Neves, G. A. Processo adsortivo de corantes por argilas esmectíticas do município de Boa Vista Paraíba. Revista Eletrônica de Materiais e Processos 2014, 9, 151. [link] 
${ }^{27}$ Oliveira, S. P.; Silva, W. L. L.; Viana, R. R. Avaliação da capacidade de adsorção do corante azul de metileno em soluções aquosas em caulinita natural e intercalada com acetato de potássio. Cerâmica 2013, 59, 338. [CrossRef]

${ }^{28}$ Mello, V.; F.; B.; J. Gama, J.; Ferreira, M.; Barauna, O.; S.; Jucá, J.; F.; T.; Motta Sobrinho, propriedades da argila esmectita na remoção de corantes têxteis. Revista matéria 2013, 18, 1467. [CrossRef]

${ }^{29}$ Dominguini, L.; Menegaro, D.; A.; T. F. Miguel, T.; F.; Dal Bó, M. Utilização de resíduos de materiais cerâmicos na adsorção de corante azul de metileno. Cerâmica 2014, 218. [CrossRef] 